\title{
Some observations on the assay of arylsuphatase A in urine
}

\author{
DF DAVIDSON
}

From the Department of Biochemistry, Ballochmyle Hospital, Mauchline, Ayrshire, Scotland

SUMMARY A method for the measurement of arylsulphatase A (ASA) in urine is assessed. Urine samples should be stored refrigerated at $4^{\circ} \mathrm{C}$ and not deep frozen prior to dialysis. The within-batch coefficient of variation of the method, in the normal range, is $6.7 \%$. The major source of imprecision is the dialysis step. The normal range is assessed and results are expressed as units per mole creatinine.

The enzyme arylsulphatase A (ASA) is defective in metachromatic leukodystrophy ${ }^{1}$ (MLD). The activity of the enzyme in urine is greatly decreased in patients with this metabolic disorder and analysis of the enzyme in urine is recommended as a screening test. ${ }^{2}$ The incidence of late infantile MLD may be as high as 1 in $40000 .^{3}$ Increased urine ASA activity is found in a wide variety of conditions including many types of cancers, during wound healing and after surgery as reviewed by Dzialoszynski and Gniot-szulzycka ${ }^{4}$ and by Posey and Morgan. ${ }^{5}$

Probably the most widely used method for arylsulphatase $\mathbf{A}$ analysis in urine is that of Baum, et al. ${ }^{6}$ In that technique, dialysed urine is incubated at $37^{\circ} \mathrm{C}$ for $1 \mathrm{~h}$ at $\mathrm{pH} 5.0$ in the presence of pyrophosphate and chloride ions. The substrate is 4-nitrocatechol sulphate. Under these conditions arylsulphatase B is largely inhibited and enzyme quantification is achieved by measuring the desulphated reaction product 4-nitrocatechol in alkaline solution by its absorbance at $515 \mathrm{~nm}$.

The purpose of the present study was to set up this method for urine arylsulphatase $A$ as a screening test for MLD.

\section{Material and methods}

Urine arylsulphatase A was measured by the method described. ${ }^{6}$ 4-nitrocatechol sulphate was obtained from the Sigma Chemical Company, London (Cat No N7005). All other chemicals were obtained from British Drug House Ltd, Poole, Dorset and were of Analar quality. Dialysis tubing $(8 \mathrm{~mm}$ width) was obtained from The Scientific Instrument Centre Ltd,

Accepted for publication 16 March 1981
London WC1. Creatinine was measured by the alkaline picrate reaction on the Technicon SMA 6/60.

All spectrophotometric measurements for ASA analysis were performed on a Pye Unicam SP1800. Random urine samples were obtained from healthy volunteers. An aliquot from each was taken for creatinine analysis. Each sample was then adjuste to $\mathrm{pH} 6 \cdot 0-6 \cdot 3$, centrifuged and then divided into two separate aliquots. One was stored in the deep freeze at $-25^{\circ} \mathrm{C}$ and the other in the refrigerator at $4^{\circ} \mathrm{C}$ prior to dialysis. Aliquots $(4.0 \mathrm{ml})$ were dialysed against cold running tap water for $18 \mathrm{~h}$ to remove interfering ions. The retentate was then carefully transferred to a $10 \mathrm{ml}$ measuring cylinder and the volume was adjusted to $6.0 \mathrm{ml}$ with deionised water. All samples were dialysed and analysed within a few days of receipt. All samples were analysed on the same day as completion of the dialysis step.

\section{Results}

SAMPLE COLLECTION AND PRESERVATION Random early morning urine samples were obtained without preservative. It was decided to use random urine samples rather than 24-hour urine collections in order to remove the problems associated with obtaining accurately timed samples. Also, prolonged collection periods may lead to an inactivation of the enzymes. ${ }^{8}$ Results were instead expressed as units of arylsulphatase $\mathrm{A}$ activity per mole of creatinine.

Urine ASA activity is expressed from the following calculation:

Units/mol creatinine

$$
=\frac{\left(A_{t}-A_{b b}\right) \times 2.5 \times 6 \times 10^{6}}{\text { creatinine }(\mathrm{mol} / 1) \times 0.5 \times 4 \times 12400 \times 60}
$$




$$
=\frac{A_{t}-A_{b l} \times 10.08}{\text { creatinine }(\mathrm{mol} / \mathrm{l})}
$$

0.5 is the sample volume in $\mathrm{ml}$.

$2.5 \mathrm{ml}$ is the total volume.

$6 / 4$ takes account of the post dialysis dilution.

60 is the incubation time in minutes.

12400 is the molar absorptivity of 4-nitrocatechol at $515 \mathrm{~nm}$.

There was a striking difference noted between the results obtained from the deep frozen samples and those stored at $4^{\circ} \mathrm{C}$. Deep frozen samples, stored and measured at the same time as those refrigerated were, on average, $39 \%$ lower in ASA activity than their refrigerated counterparts.

The stability of five dialysed urines stored in the refrigerator at $4^{\circ} \mathrm{C}$ showed an average loss of activity of $3.8 \%$ in $24 \mathrm{~h}$ and $5.6 \%$ in 8 days. After two months storage at $4^{\circ} \mathrm{C}$, five dialysed urines showed variable losses in activity ranging from $8.5 \%$ to $63.4 \%$. Five undialysed urines stored deep frozen for two months showed virtually no measurable activity.

The stability of the final coloured alkaline solution obtained during ASA assay was assessed over a three-hour period during which five reaction tubes were maintained at room temperature $\left(20^{\circ} \mathrm{C}\right)$ in full daylight. The mean decrease in absorbance at $515 \mathrm{~nm}$ of the test solutions was $10 \cdot 2 \%$. Over this same time period the absorbance of the respective blank solutions more than doubled in value.

\section{PRECISION}

Within batch precision was assessed by preparing 15 aliquots of a fresh pooled human urine from healthy individuals. Each aliquot was then adjusted to $\mathrm{pH} 6 \cdot 0-6 \cdot 3$, centrifuged and dialysed against cold running tap water for $18 \mathrm{~h}$ prior to ASA assay.

Within batch precision of the assay step, only, excluding the contribution to imprecision of the dialysis step, was also determined. One of the above 15 dialysed urine samples was itself divided into 15 aliquots and assayed separately for ASA. The results are presented in Table 1 .

Since the total assay variance is equal to the sum of the individual variances, the standard deviation
Table 1 Within batch precision of urine arylsulphatase $A$ assay

\begin{tabular}{lll}
\hline & $\begin{array}{l}\text { Total assay }(\text { U/l) } \\
\text { (including dialysis step) }\end{array}$ & $\begin{array}{l}\text { Assay step only } \\
(\text { U/l) }\end{array}$ \\
\hline n & 15 & 15 \\
Mean & 1.95 & 1.85 \\
SD & $0 \cdot 13$ & 0.041 \\
CV & $6.69 \%$ & $2.20 \%$ \\
\hline
\end{tabular}

(SD) of the dialysis step alone may be estimated from the equation:

$$
\mathrm{SD}^{2} \text { total }=\mathrm{SD}^{2} \text { assay }+\mathrm{SD}^{2} \text { dialysis. }
$$

In this way the SD of the dialysis step is found to be $0 \cdot 12 \mathrm{U} / \mathrm{l}$ and represents, by far, the greatest source of imprecision of the method, as may be expected.

\section{NORMAL RANGES}

Random morning urine samples were obtained from:

(i) Seventeen healthy laboratory staff comprising 10 men and 7 women ranging in age from 21 to $36 \mathrm{yr}$.

(ii) Twenty-six apparently healthy children comprising 15 boys and 11 girls in age range $1 \frac{1}{2}$ to $13 \mathrm{yr}$.

The frequency distribution for all 43 samples showed a significant positive skewness for urine ASA activity uncorrected for creatinine excretion. This finding was also noted by Thomas and Howell in a similar study. ${ }^{2}$

The occurrence of high outlying values was greatly reduced by expressing the enzyme activity per mole creatinine. However, this procedure did not abolish the obvious positive skewness. The results of ASA activity were converted to an apparently normal distribution by logarithmic transformation as noted by other workers. ${ }^{7}$ It was in this form that subsequent statistical calculations were made.

The results of these calculations are given in Tables 2 and 3.

Table 2 shows a significant difference in urine ASA activity, uncorrected for creatinine, between adults and children ( $p<0.02)$.

This is at variance with the findings of Thomas and Howell $^{2}$ who found no such obvious difference. In

\begin{tabular}{|c|c|c|c|c|c|c|}
\hline & \multicolumn{2}{|c|}{ Urine ASA $(U / l)$} & \multicolumn{2}{|c|}{ Urine creatinine ( $\mathrm{mmol} / \mathrm{l})$} & \multicolumn{2}{|c|}{ Urine $A S A(U / m o l$ creatinine $)$} \\
\hline & Adults & Children & Adults & Children & Adults & Children \\
\hline $\begin{array}{l}\text { n } \\
\text { Mean }\end{array}$ & $\begin{array}{l}17 \\
2 \cdot 3\end{array}$ & $\stackrel{26}{1 \cdot 2}$ & $\begin{array}{l}17 \\
16 \cdot 6\end{array}$ & $\begin{array}{l}26 \\
10 \cdot 4\end{array}$ & $\begin{array}{r}17 \\
152\end{array}$ & $\begin{array}{r}26 \\
127\end{array}$ \\
\hline $\begin{array}{l}\mathrm{p} \\
\text { Overall range }\end{array}$ & \multicolumn{2}{|c|}{$<0.02$} & \multicolumn{2}{|c|}{$<0.002$} & \multicolumn{2}{|c|}{$\begin{array}{r}\mathrm{NS} \\
18-473\end{array}$} \\
\hline
\end{tabular}

Table 2 Comparison of results between adults and children 
Table 3 Comparison of results between males and females

\begin{tabular}{|c|c|c|c|c|c|c|}
\hline & \multicolumn{2}{|c|}{ Urine $A S A(U / l)$} & \multicolumn{2}{|c|}{ Urine creatinine ( $\mathrm{mmol} / \mathrm{l}$ ) } & \multicolumn{2}{|c|}{ Urine ASA (U/mol creatinine) } \\
\hline & Males & Females & Males & Females & Males & Females \\
\hline $\begin{array}{l}\text { n } \\
\text { Mean }\end{array}$ & $\begin{array}{l}25 \\
2 \cdot 0\end{array}$ & $\begin{array}{l}18 \\
1 \cdot 1\end{array}$ & $\begin{array}{l}25 \\
13 \cdot 6\end{array}$ & $\begin{array}{l}18 \\
11 \cdot 7\end{array}$ & $\begin{array}{r}25 \\
162\end{array}$ & $\begin{array}{r}18 \\
107\end{array}$ \\
\hline $\begin{array}{l}\mathrm{p} \\
\text { Overall range }\end{array}$ & \multicolumn{2}{|c|}{$<0.02$} & \multicolumn{2}{|c|}{$\begin{array}{c}\text { NS } \\
3 \cdot 9-31 \cdot 3\end{array}$} & \multicolumn{2}{|c|}{$<0.05$} \\
\hline
\end{tabular}

that study the statistical details were not presented.

There is however, a significant difference between adults and children for urine creatinine concentration $(p<0.002)$ as would be expected. When results of urine ASA activity are expressed as $U /$ mole creatinine there is no longer a statistically significant difference between adults and children. There is also a significant difference between males and females for urine ASA uncorrected for creatinine as shown in Table $3(p<0.02)$. There was found to be no significant difference for urine creatinine concentration between the two groups. When results are expressed as $\mathrm{U} / \mathrm{mole}$ creatinine, the significant difference between males and females persists $(\mathrm{p}<0.05)$.

The observed range of values for uncorrected urine ASA activity with this method compares favourably with those quoted in the literature. Baum et al. ${ }^{6}$ found values from 10 healthy adult males to range from $0.41 \mathrm{U} / 1$ to $2.40 \mathrm{U} / \mathrm{l}$. Thomas and Howell ${ }^{2}$ examined a control group of 160 individuals whose urine activities ranged from $0 \cdot 14 \mathrm{U} / 1$ to $17 \cdot 6 \mathrm{U} / 1$.

\section{Discussion}

From the data presented, it can be seen that samples for urinary ASA analysis should be stored refrigerated and not deep-frozen prior to dialysis. The assay should be carried out with the minimum of delay.

Arylsulphatase $\mathbf{A}$ is an enzyme which consists of a variety of subunits. ${ }^{78}$ It may be that the process of freezing and thawing disrupts this subunit structure and results in a loss of activity.

In the proposed selected method for the measurement of ASA in urine, ${ }^{5}$ it is noted that dialysed urine was stable for as long as 18 days at $-20^{\circ} \mathrm{C}$. It may be that dialysis confers stability to the urine enzyme or else that the inactivation process had already taken place and the activity remaining was subsequently stable.

From the assay precision data it is clear that a rigid standardised dialysis procedure would greatly improve assay precision since the dialysis step is by far the largest contributer to assay imprecision. The following suggestions are made in an attempt to minimise the imprecision of the dialysis step. (a) The same batch of dialysis tubing should be used for each batch of analyses to minimise imprecision due to variations in membrane thickness;

(b) All analyses, including the dialysis step, could be carried out in duplicate;

(c) The rate of diffusion across a dialysis membrane is proportional to its cross sectional area. Therefore care should be taken to ensure that dialysis tubing of identical length is used;

(d) Care is required in the transfer of the dialysed sample from the tubing to an appropriately small measuring cylinder;

(e) Constant mechanical stirring could also be used during overnight dialysis.

Good assay precision is particularly important in the investigation of MLD when the decision level between normal and abnormal results occurs at a low level of urine enzyme activity. The contributio to the total assay $\mathrm{CV}$, of the dialysis step alone, at of around the lower limit of normal, is of the order of $50 \%$ and could be even higher. This will inevitably contribute to a wide overlap between normals and abnormals and a generously high lower limit of normal is advocated.

ASA excretion in urine shows a significant diurnal variation. Maximum output occurs between 6 am and 9 am and this is the period during which a random urine sample should be obtained. ${ }^{8}$

From the information obtained in this study it would be appropriate that samples, suitably collected and preserved, which exhibited values for urine ASA of less than $40 \mathrm{U} / \mathrm{mole}$ creatinine would be suitable candidates for further investigation.

The author wishes to thank the staff of the Ayrshire Area Laboratory and their families for kindly providing the urine samples used in this study.

\section{References}

${ }^{1}$ Stumpf D, Neuwelt E, Austin J, Kohler P. Metachromatic Leukodystrophy (MLD). X Immunological studies of the abnormal sulfatase A. Arch Neurol 1971;25:427-31.

2 Thomas GH, Howell RR. Arylsulphatase A activity in human urine: Quantitative studies on patients with lysosomal disorders including metachromatic leukodystrophy. Clin Chim Acta 1972;36:99-103.

${ }^{3}$ Dulaney JT, Moser HW. Sulfatide lipidoses: metachromatic leukodystrophy. In: Stanbury JB, Wyngaarden 
JB, Fredrickson DS, eds. The metabolic basis of inherited disease. New York: McGraw-Hill, 1978:770-809.

${ }^{4}$ Dzialoszynski LM, Gniot-szulzycka J. Some clinical aspects of arylsulphatase activity. Clin Chim Acta 1967;15:381-6.

${ }^{5}$ Posey LE, Morgan LR. Measurement of arylsulphatase A activity in urine. Clin Chem 1979;25:328-31.

- Baum H, Dodgson KS, Spencer B. The assay of arylsulphatases A and B in human urine. Clin Chim Acta 1959;4:453-5.

${ }^{7}$ Werner M, Heilbron DC, Maruhn D, Atoba M. Patterns of urinary enzyme excretion in healthy subjects. Clin Chim
Acta 1970;29:437-49.

8 Maruhn D, Strozyk K, Gielow L, Bock DK. Diurnal variations of urinary enzyme excretion. Clin Chim Acta $1977 ; 75: 427-33$.

Requests for reprints to: Mr DF Davidson, Department of Biochemistry, Ballochmyle Hospital, Mauchline, Ayrshire, Scotland KA5 6LQ. 